\title{
Explorando o mundo sem sair de casa
}

DOI: dx.doi.org/10.18616/nrm03

Hexael Demarch Lisiane Tuon Luciane Bisognin Ceretta Renan Antônio Ceretta Vitória Bisognin Ceretta

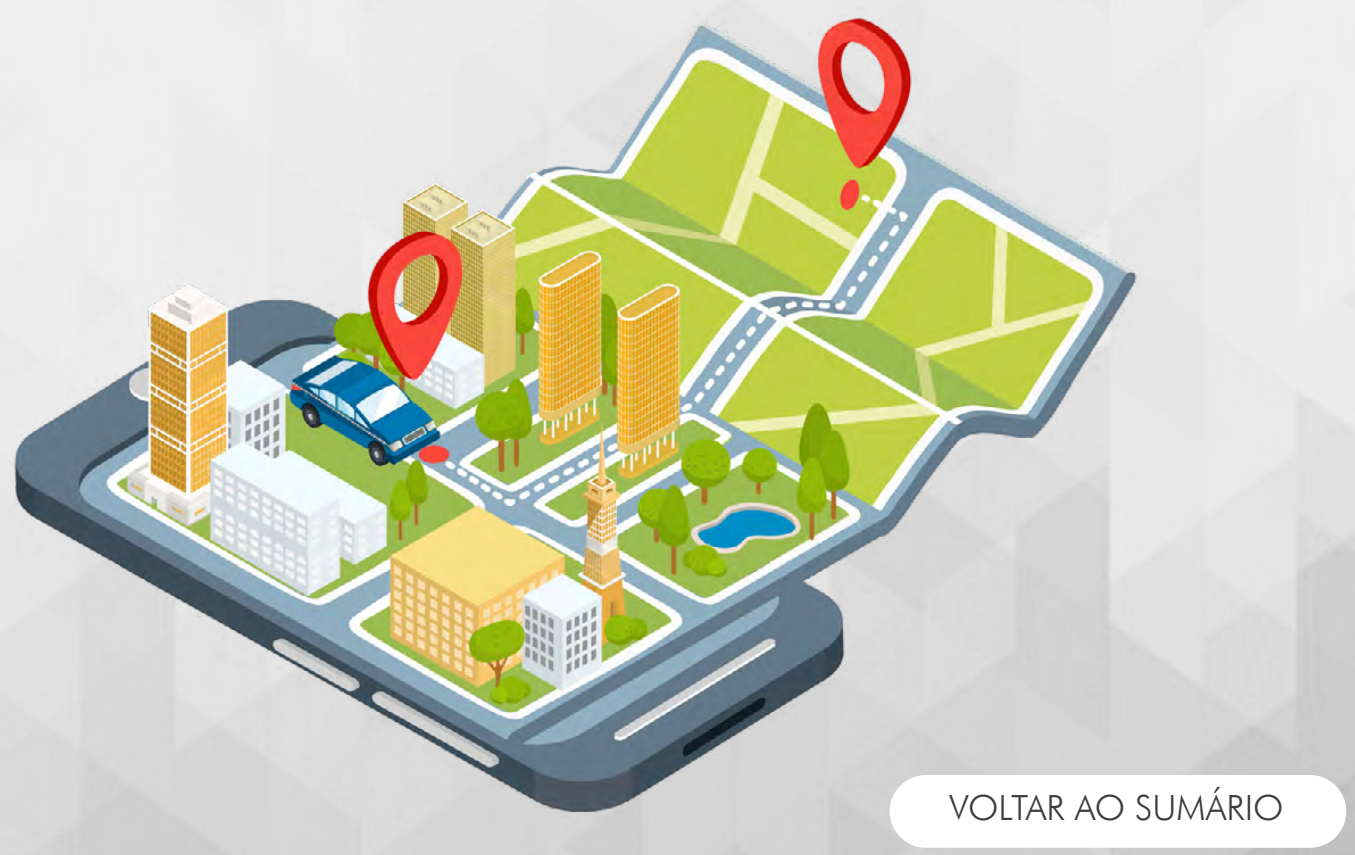


Em meio ao distanciamento social proposto nestes tempos de combate à Covid-19, é importante a utilização de meios e ferramentas que possam permitir à população atividades de lazer e entretenimento sem sair de casa. Dessa forma, a internet vem contribuindo como o principal meio para a união das pessoas e pela busca de recursos para passar o tempo.

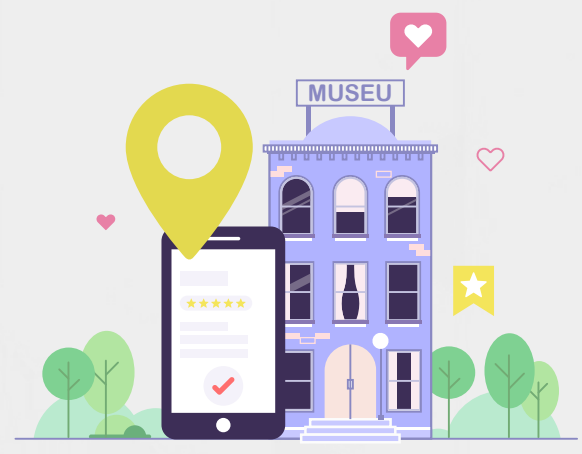

Graças às inovações tecnológicas, é possível visitar lugares, aprender novos idiomas e comunicar-se enquanto se está praticando o distanciamento social necessário. Pensando nisso, trouxemos uma lista com alguns sites que poderão ajudar você a explorar o mundo no conforto do lar.

\section{Pinacoteca}

Pina Localizada no centro da cidade de São Paulo, a Pinacoteca - Museu de artes visuais mais antigo da cidade - pode ser visitada, também, de maneira virtual. Seu acervo permanente está disponível no site do museu, com uma vista em $360^{\circ}$ das salas e informações das obras expostas. Além disso, foram também disponibilizados filmes presentes no acervo do museu para serem assistidos durante o distanciamento social (PINACOTECA, 2020).

\section{Visita on-line}

\section{Acervo de filmes}

\section{Casa de Anne Frank}

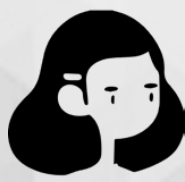

O museu, situado em Amsterdã e que retrata a realidade de Anne Frank, uma menina judia, vítima do Holocausto, que viveu em um esconderijo com sua família durante a Segunda Guerra, também está disponível para uma visita virtual através do Google Arts \& Culture. Nessa visita, é possível passear pelos cômodos da casa que serviu de abrigo para a menina.

\section{Visita on-line}




\section{Harry Potter: Uma história mágica}

68

11

Harry Potter: Uma história mágica é uma exposição realizada na Biblioteca Britânica, em Londres, e que pode ser acessada através do Google Art \& Culture. A exposição é uma viagem para dentro do universo de Harry Potter, mostrando inclusive manuscritos e objetos mágicos.

\section{Visita on-line}

\section{Santuário histórico de Machu Picchu}

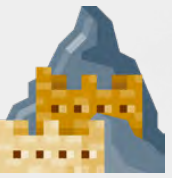

Através do site Google Art \& Culture, também é possível fazer uma visita ao santuário histórico de Machu Picchu, a cidade perdida dos incas.

\section{Visita on-line}

\section{Curtas}

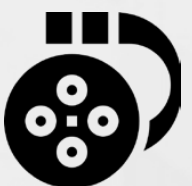

No Youtube é possível acessar diversos curta-metragens de forma gratuita, inclusive nomes como "Hair love" (vencedor de melhor curta de animação do Oscar de 2020) - que conta a história de um pai com dificuldades para ajudar a filha a arrumar o cabelo - e "Kitbull” (animação da Pixar) - que retrata a história de amizade de um gato e um pitbull, também indicado a melhor curta de animação do Oscar de 2020.

Hair Love

\section{Kitbull}

\section{Canal Elisabeth Wagner - Para aprender inglês}

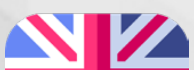

O Canal da Elisabeth vem ensinando inglês de forma gratuita no Youtube desde o ano de 2011 - apresentando o novo idioma $\nabla / \mathbf{N}$ de uma maneira fácil e tranquila, fazendo com que o aprendizado ocorra de forma natural. São diversos vídeos que poderão ajudar quem deseja treinar ou começar a ter contato com a língua inglesa.

\section{Acessar}

